\title{
Ontogeny and Season Constrain the Production of Herbivore-Inducible Plant Volatiles in the Field
}

\author{
J. Daniel Hare
}

Received: 2 July 2010 /Revised: 10 September 2010 / Accepted: 26 October 2010 / Published online: 9 November 2010

(C) The Author(s) 2010. This article is published with open access at Springerlink.com

\begin{abstract}
Herbivores may induce plants to produce an array of volatile organic compounds (herbivore-induced plant volatiles, or HIPVs) after damage, and some natural enemies of herbivores are attracted by those HIPVs. The production of HIPVs by the undomesticated species Datura wrightii was quantified in response to damage by its natural community of herbivores or the plant hormone methyl jasmonate (MeJA) over plant's 6-month growing season. Patterns of HIPV production were compared to the seasonal abundance of $D$. wrightii's two most abundant herbivores, the chrysomelid beetle Lema daturaphila and the mirid bug Tupiocoris notatus, and their shared generalist predator, the lygaeid bug Geocoris pallens. HIPV production was especially high in the spring, when plants were growing vegetatively, but HIPV production declined after plants began to flower and produce fruit, and these volatiles no longer were inducible by September. The composition of the HIPV blends also changed seasonally. HIPV production and composition were partially restored by "rejuvenating" plants back to the vegetative growth stage independently of season by cutting them back and allowing them to resprout and regrow vegetatively. HIPV production of $D$. wrightii in the field is limited to the earlier ontogenetic stages of growth, despite the fact that both herbivores and their shared natural enemy inhabited plants throughout the full season. The adaptive value of HIPV production in D. wrightii may
\end{abstract}

Electronic supplementary material The online version of this article (doi:10.1007/s10886-010-9878-z) contains supplementary material, which is available to authorized users.

\section{J. D. Hare $(\bowtie)$}

Department of Entomology, University of California,

3401 Watkins Drive,

Riverside, CA 92521, USA

e-mail: daniel.hare@ucr.edu be constrained by plant ontogeny to the vegetative stages of plant growth.

Key Words Induced defense - Ontogenetic variation . Datura wrightii $\cdot$ Lema daturaphila Indirect defense. HIPVs · Tritrophic interactions

\section{Introduction}

Numerous plant traits may be altered by biotic or abiotic stresses. One such trait involves the production of volatile organic compounds after plants are attacked by herbivorous insects. Plants damaged by the feeding activity of herbivorous insects release herbivore-induced plant volatiles (HIPVs), the production of which is mediated by the jasmonate signaling pathway. Additionally, HIPVs may serve as cues that aid in the discovery of herbivores by the natural enemies of those herbivores (Turlings and Wäckers, 2004; Allison and Hare, 2009). Natural enemies utilize a range of chemical cues with different properties to guide them through the stepwise process of first locating a damaged plant, then locating a potential host on that plant, and ultimately assessing the quality of a host individual for utilization (Vinson, 1976). The HIPVs produced by plants may serve as relatively long distance cues to signify that a plant may be infested with potential hosts, although "long distance" rarely is defined (Puente et al., 2008b). After locating a damaged plant, natural enemies then may utilize more specific cues to locate and identify proper hosts on a damaged plant. In many cases, an array of volatile organic compounds similar to that induced by herbivore damage can be induced by treating plants with jasmonic acid or methyl jasmonate (MeJA) (Hopke et al., 1994; Dicke et al., 1999; Hare, 2007). However, in other cases, damage by 
herbivores elicits different quantities and blends of HIPVs than do jasmonates (Bruinsma et al., 2009).

Research on other feeding-induced plant responses often shows substantial seasonal or ontogenetic variation in their magnitude (Stout et al., 1996; Thaler et al., 1996; Karban and Baldwin, 1997). Such findings suggest that these induced responses may be best developed in, and perhaps limited to, relatively young plants or plant tissues (Karban and Myers, 1989).

In contrast to inducible direct defenses, the potential for seasonal variation in HIPV production has received minimal study. In maize (Zea mays), HIPV production in seedlings is inducible, but HIPV production in mature leaves apparently is not (Köllner et al., 2004). In soybean (Glycine max), feeding by the fall armyworm, Spodoptera frugiperda, induced ca. ten times the total HIPVs from leaves of 5-wkold non-flowering vegetative plants compared to 10-wk-old flowering plants (Rostas and Eggert, 2008).

Although the study of induced HIPVs in cultivated species in the laboratory has logistic advantages, it is difficult to draw strong inferences on the evolution and maintenance of HIPV production in cultivated species because the interacting species often are far removed from their evolutionary context. One natural system in which such limitations can be overcome involves the native, undomesticated plant species, Datura wrightii (Solanaceae) and its native herbivores and natural enemies. In the laboratory, young plants of this species produce similar blends of HIPVs either when fed upon by the specialist chrysomelid beetle Lema daturaphila, or when treated with MeJA (Hare, 2007).

Unlike most of the rapidly-growing annual species in which HIPV production has been studied, D. wrightii has a long growing season in the sage scrub habitats of inland southern California. Seeds germinate in March or April after winter rains, but flowering usually is not initiated until June, after which plants continue to grow while also producing flowers and seed capsules through November. The plant is perennial, and plants may produce new sprouts from the root crown as early as February.

Within southern California populations, D. wrightii exhibits two leaf trichome phenotypes, and aspects of the ecology and genetics of the trichome dimorphism have been described elsewhere (van Dam and Hare, 1998; van Dam et al., 1999). The 'velvety' phenotype is densely covered by short, non-glandular trichomes and feels velvety to the touch, whereas the 'sticky' phenotype is less densely covered with glandular trichomes that secrete esters of glucose and aliphatic acids, and these leaves feel sticky to the touch. The trichome phenotype is governed by a single locus and is inherited in a Mendelian fashion; the allele for the sticky phenotype is dominant over that of the velvety phenotype (van Dam et al., 1999). Seedlings, new sprouts produced during the spring, and even new sprouts produced in mid-season after plants have been completely defoliated, all produce leaves that are covered with glandular trichomes (Elle et al., 1999). In all cases, however, the homozygous recessive genotype soon begins to produce leaves with a progressively greater proportion of nonglandular trichomes until differentiation to the velvety phenotype is completed (van Dam et al., 1999).

The herbivore community that attacks $D$. wrightii is relatively simple, being comprised of some five to ten species, depending upon season and location (Elle and Hare, 2000; Hare and Elle, 2002). The most abundant herbivore species overall is Lema daturaphila, a folivore whose adult and larval stages impose chronic, season-long herbivory on both trichome phenotypes. On sticky plants, the most abundant herbivore is the mirid bug, Tupiocoris notatus. This insect punctures and kills leaf cells while removing their contents. Both species are multivoltine and feed on $D$. wrightii throughout the plant's growing season. Other herbivores usually are less abundant and more limited seasonally in their occurrence (Elle and Hare, 2000).

A number of generalist natural enemies are associated with the herbivores of $D$. wrightii, but the most abundant is the predaceous western big-eyed bug, Geocoris pallens (Heteroptera: Lygaeidae). This is one of several generalist predators that is more effective against both $L$. daturaphila and $T$. notatus when the herbivores are on velvety rather than on sticky plants (Gassmann and Hare, 2005). Individual components of the HIPV blends of other plant species are known to attract G. pallens (Kessler and Baldwin, 2001; Halitschke et al., 2008), and this suggests that this predator may be attracted to some key compounds within a blend regardless of the blend's overall composition. This predator also inflicts higher mortality on eggs and young larvae of L. daturaphila on herbivore-damaged or MeJA-treated D. wrightii plants than on undamaged or untreated plants (J. D. Hare, pers. obs.).

In order to understand the potential for $D$. wrightii to release HIPVs that may attract natural enemies of its herbivores, this study analyzed the HIPV production of fieldgrown $D$. wrightii plants that were damaged by resident herbivore populations. Abundances of L. daturaphila, $T$. notatus, and G. pallens were monitored to determine how the seasonal production of HIPVs might relate to seasonal abundance patterns of the historically most abundant herbivores and their natural enemy. The goal was to test the null hypothesis of no qualitative or quantitative variation in induced HIPV production during the growing season. If the null hypothesis were rejected, then the variation in HIPV production might be caused either by variation in abiotic factors, such as temperature and relative humidity, that are known to vary over the growing season as well as to affect HIPV production (Gouinguene and Turlings, 2002), or by 
ontogenetic changes in plants that are normally correlated with seasonal development. Seasonal variation in HIPV production indeed was observed. Therefore, additional experiments were performed on other plants using MeJA to control more precisely the process of induction to separate the effects of ontogenetic development of plants from seasonal variation in abiotic parameters on qualitative and quantitative variation in HIPV production.

\section{Methods and Materials}

Study Site Experiments were carried out in two adjacent fields at the experimental farm of the University of California, Riverside. In one field, plants were attacked naturally by a resident population of herbivores, whereas plants in the other field were induced by MeJA. To control for possible genetic variation in HIPV production, only plants of the highly inducible MVV6 and MVV8 lines (Hare, 2007) were used. All plants were backcross progeny of heterozygote sticky pollen acceptors and their original homozygous recessive velvety pollen parent for four (herbivory plot) or five (MeJA-induced plot) generations.

The collection of volatiles from herbivore-damaged plants, and herbivore and natural enemy abundances were monitored in a 2-yr-old field plot of plants that was maintained in a 'naturalized' condition with minimal weed control and no irrigation after the normal winter rains. Both herbivore and natural enemy populations had become established in this field, and surviving velvety plants were more abundant than sticky plants by the time this experiment was initiated.

For collection of volatiles from plants with better control of the timing and level of induction, a second plot was established $0.1 \mathrm{~km}$ away. Given the size of mature plants ( $1 \mathrm{~m}$ in height and $3 \mathrm{~m}$ in diam., Hare et al., 2003), it would have been impractical to attempt to induce these experimental plants to the same extent and at the same time with natural herbivory, so precisely-timed applications of MeJA were used instead. The separation of this plot from the herbivore-infested plot aided in keeping this plot free from herbivores and the plants uninduced prior to MeJA application.

For this plot, seeds were planted in a seedling flat on 24 January, 2009, stratified in a cold room $\left(5.6^{\circ} \mathrm{C}\right)$ for $10 \mathrm{~d}$, then placed in an incubator with alternating day and night temperatures $\left(16: 8 \mathrm{~L}: \mathrm{D}, 30^{\circ}: 20^{\circ} \mathrm{C}\right)$. After $21 \mathrm{~d}$, seedlings were transplanted to $10 \mathrm{~cm}$ pots and kept in the greenhouse $\left(15^{\circ}-30^{\circ} \mathrm{C}\right)$, with natural illumination extended to $16 \mathrm{~h} / \mathrm{d}$ with sodium vapor lamps.

There were 10 blocks of 16 plants spaced $2.3 \mathrm{~m}$ apart within and between rows, and blocks were separated from each other by $8.4 \mathrm{~m}$ of bare ground. The area was treated with a pre-emergence herbicide (Trifluralin at the rate of $668 \mathrm{ml} / \mathrm{ha}$ ). The plot was furrow-irrigated prior to transplanting for $24 \mathrm{~h}$, then for $8 \mathrm{~h} 3$ days after transplanting, and weekly for $8 \mathrm{~h}$ for three wk thereafter. The plants were not irrigated after 21 April, 2009, and no rainfall occurred during the experiment. The absence of any rainfall during the spring and summer is characteristic of the sage scrub habitat in which $D$. wrightii commonly occurs. Seedlings were transplanted to the field prior to differentiation of adult trichome type to facilitate establishment on 31 March, 2009 , but this precluded having equal numbers of sticky and velvety plants in each block. After differentiation was complete, the observed frequency of sticky to velvety plants over all blocks was 82 sticky: 78 velvety, not significantly different from an expected $1: 1$ ratio for these backcross progeny. Plants were treated weekly, except during the weeks when volatiles were collected, with prophylactic applications of acephate (Orthene 97, Valent Chemical Co., Walnut Creek, CA, USA $1.2 \mathrm{~g} / \mathrm{l}$ ) in water to protect them from herbivory. Preliminary experiments showed that acephate alone did not induce HIPVs.

Induction and HIPV Collection in the Field Field procedures utilized aeration chambers, air lines, and traps of the same design as used previously in the laboratory (Hare, 2007). Aeration chambers were made from polyester cooking bags (unprinted $45 \times 55 \mathrm{~cm}$ bags, Terinex, Bedford, U.K.). HIPVs were adsorbed on traps made of $4.6 \mathrm{~mm}$ O.D. glass tubing and filled with $25 \mathrm{mg}$ of Super-Q (Alltech, State College, PA, USA). Air was introduced into the bag through PTFE tubing (4.6 mm O.D.) and was withdrawn from the bags through the traps through PVC tubing (4.6 mm I.D.) downstream of the traps. Air flow was provided by two 12-V portable air pumps (Model \# MOAP125-JH, Gast Manufacturing, Benton Harbor, MI, USA). One pumped air to the bags and the other withdrew it. A 12-V deep-cycle marine battery powered both pumps. A manifold with 16 pairs of flow meters (Aalborg Instruments, Orangeburg, NY, USA) was constructed so that inlet and exhaust flow to and from 16 sampling bags could be precisely and independently regulated at $1.0 \mathrm{l} / \mathrm{min}$ for each plant. Inlet air was drawn through a filter of activated charcoal placed between the pump and the manifold. Preliminary studies showed that the charcoal filter was sufficient to remove all ambient HIPVs.

Because the canopies of mid-season plants are comprised of several thousand leaves (Hare et al., 2003), it was not possible to sample HIPV production from the whole plant. An aeration bag was placed over the terminal leaves of a branch and secured with a twist-tie around the stem. The bag enclosed 4-6 full-sized leaves and a similar number of growing leaves. Branches with flowers were not used to avoid confounding floral volatiles with foliar 
HIPVs. Volatiles were collected for $90 \mathrm{~min}$. At the termination of the aeration, traps were wrapped in aluminum foil, labeled, returned to the laboratory, and stored at $-20^{\circ} \mathrm{C}$ for extraction later that day. Two groups of 16 plants were aerated each day, usually from $08.30 \mathrm{~h}$ until $10.00 \mathrm{~h}$, and from $11.00 \mathrm{~h}$ until $12.30 \mathrm{~h}$.

Plants to be treated with MeJA were aerated twice, once prior to MeJA treatment and once afterward. As bags were removed from the aeration prior to MeJA treatment, the twist-ties were reattached to the branch where they sealed the bag to serve as a marker so that precisely the same leaves could be aerated after MeJA treatment. The upper surfaces of all leaves were sprayed with a solution of $8 \mathrm{mM}$ MeJA in $0.1 \%$ Tween $20^{\circledR}$ in water just to run-off after the pretreatment aeration. This rate was chosen because it induced similar quantities of HIPVs as feeding by $L$. daturaphila in laboratory experiments (Hare, 2007). Plants were aerated a second time on the 3rdday following treatment. After posttreatment aeration, the aerated branches were clipped, brought to the laboratory, then all aerated leaves were removed and dried $\left(80^{\circ} \mathrm{C}\right.$ for $\left.48 \mathrm{~h}\right)$ to determine dry mass. A preliminary experiment showed that $0.1 \%$ Tween 20 alone did not induce HIPVs. After both aerations in a natural state, plants were "rejuvenated" by cutting them back to the root crown and allowing them to resprout and produce new foliage. After a month, plants were once again aerated before and after treatment with MeJA.

Herbivore-damaged plants were aerated only once. Because they were all being damaged, no pre-treatment aeration was possible. For both trichome phenotypes, branches were selected with actively feeding, 2nd or older instars of $L$. daturaphila, but larvae were removed prior to aeration. Sticky plants also were attacked by T. notatus, which also were removed prior to aeration. After aeration, the aerated leaves were removed and brought back to the laboratory. The percent defoliation averaged over all aerated leaves was estimated by a trained person before leaves were dried, as above, and the same person made all estimates throughout the experiment.

Five series of aerations were completed at $5 \mathrm{wk}$ intervals, starting the week of 27 April, 2009, and concluding the week of 14 September, 2009. Uninduced plants were aerated on Mondays and Tuesdays, herbivore-damaged plants were aerated on Wednesdays, and MeJA-induced plants were aerated on Thursdays and Fridays. All aerations took place under clear skies and full sunlight and were typical of inland southern California in all respects. Data on air temperature, relative humidity, and light intensity, recorded hourly from $09.00 \mathrm{~h}$ until $13.00 \mathrm{~h}$, were obtained from records from the California Irrigation Management Information System (CIMIS) weather station located at the UC Riverside experimental farm (supporting information Table S1). A total of 736 aerations were planned over the season, but data from 18 were lost due to random accidents such as leaky or punctured bags, leaving a total of 718 aerations: 561 aerations from MeJA-treated and rejuvenated plants and 157 from plants naturally damaged by herbivores.

Volatiles were eluted from the traps with $150 \mu \mathrm{l}$ of $\mathrm{CH}_{2} \mathrm{Cl}_{2}$ containing $4 \mathrm{ng} / \mu \mathrm{l}$ of 1-bromoheptane as an internal standard into autosampler vials with $250 \mu$ l glass inserts and sealed with crimp caps and PTFE-lined rubber septa. Samples were analyzed by gas-liquid chromatography largely as described in Hare (2007) except that a shorter column (DB-5, $30 \mathrm{~m}, 0.25 \mathrm{~mm}$ ID, $0.25 \mu \mathrm{m}$ film thickness, $\mathrm{J} \& \mathrm{~W}$ Scientific, Folsom, CA, USA) and an autoinjector (Hewlett-Packard 7673) were used. To confirm identifications, selected samples were analyzed with a HewlettPackard 6890 gas chromatograph coupled to a HewlettPackard 5973 mass selective detector, and the mass spectra and retention times of compounds were matched with those of authentic standards as described in Hare (2007). Peak quantification in units of $\mathrm{ng}^{\circ} \mathrm{g}^{-1}$ leaf (dry wt.) $\mathrm{h}^{-1}$ was made using Agilent ChemStation ${ }^{\circledR}$ software based on comparison of their peak height with that of the internal standard.

Insect Abundances Insect censuses were taken at $2 \mathrm{wk}$ intervals from 1 May through 25 September, 2009. For each census, up to 16 plants, 8 sticky and 8 velvety, were randomly selected, and a sleeve cage was placed around the base of each plant with the lower drawstring tied around the base of the plant. The cage remained open to allow recolonization of any arthropods that were disturbed by placing the cage around the plant. On the next day, the sleeve cage was quickly drawn around the plant, and the upper drawstring was tied to fully cage the plant, then the plant was cut at the base and returned to the laboratory. Plants were placed in plastic trash bags, and all arthropods were anesthetized with $\mathrm{CO}_{2}$. Cages were opened, and all insects were removed, counted, and placed in labeled vials with $70 \%$ ethyl alcohol. Abundances of $L$. daturaphila and G. pallens are reported for each sampling date for both sticky and velvety plants, but abundances of $T$. notatus are reported only for sticky plants because $T$. notatus rarely occurs on velvety plants (Hare and Elle, 2002).

Statistical Analyses Analyses were carried out on total HIPVs, calculated as the sum of all individual HIPVs per plant, followed by multivariate analyses on the HIPV blend because the quantities of individual HIPVs were intercorrelated (van Dam and Poppy, 2008). I used PROC PRINCOMP of SAS (SAS Institute, 2008) to conduct an exploratory Principal Components Analysis (PCA) based upon the covariance matrix of all 718 samples to calculate a smaller number of uncorrelated components that were linear combinations of the original variables and to identify particular components contributing most to the patterns of variation in 
HIPV production. The factor loadings show how much each of the original variables contributes to each new component, and factor scores for the new components were calculated for each original observation. General patterns of variation illustrated by bivariate plots of the factor loadings and means of factor scores were explored further with restricted maximum likelihood (REML) analyses of variance (ANOVA) on the individual HIPVs with greatest factor loadings. Repeated measures ANOVAS using PROC MIXED of SAS were used to compare HIPV production of nonrejuvenated and rejuvenated plants before and after MeJA treatment. These models also included trichome type and aeration date, and all interactions as fixed effects. Where appropriate, two-way interactions were decomposed using the SLICE option of PROC MIXED. REML approaches to ANOVA are more appropriate than conventional approaches (e.g., PROC GLM of SAS) when sample sizes are unequal. In all models, 'block' (e.g., the group of 16 plants) was included as a random factor but was deleted from the final model when not statistically significant. For all HIPV analyses, the $\log _{10}(x+1)$ transformation was used to ensure normality of errors; the $\mathrm{x}+1$ transformation was required because a few plants produced no detectable HIPVs, especially late in the season.

Analysis of covariance (ANCOVA) was used to analyze $\log _{10}$-transformed HIPV production of herbivore-damaged plants. Aeration date, trichome type, and their interaction were included as fixed effects, and percent defoliation was included as a covariate. Insect abundances also were analyzed by restricted maximum likelihood ANOVA after the $\log _{10}(\mathrm{x}+1)$ transformation using a model that including sampling date, trichome phenotype, and their interaction as fixed treatment effects.

\section{Results}

HIPVS in the Field In general, the group of compounds detected was similar to those reported in a previous laboratory study (Hare, 2007). Abundant compounds included $(E)-\beta$ ocimene, (E)- $\beta$-caryophyllene, (Z)-3-hexenyl acetate, and (E)-4,8,dimethyl-1,3,7 nonatriene (hereafter DMNT). Other components of more limited abundance and occurrence included limonene, linalool, an isomer of bergamotene, $\alpha$ humulene, $\beta$-selinene, nerolidol, and $(E, E)-4,8,12$ trimethyl-1,3,7,11 tridecatetraene (hereafter TMTT). In contrast to the laboratory studies, methyl salicylate, $(E, E)$ $\alpha$-farnesene, and geranyl acetone were detected occasionally from plants aerated in the field. Basic statistics for all compounds are available in supporting information Table $\mathrm{S} 2$.

HIPV production by herbivore-damaged plants varied significantly over time (ANCOVA, date effect $F_{4,132}=$ 44.04, $P<0.001$, Fig. 1a). In April, defoliation averaging
$7.3 \%$ and $8.3 \%$ on sticky and velvety plants, respectively, resulted in the production of over 2,500 $\mathrm{ng}$ total HIPVs $\mathrm{g}^{-1}$ leaf tissue (dry wt.) $\mathrm{h}^{-1}$. In June, defoliation of 4.9 and $10.5 \%$ on sticky and velvety plants resulted in the production only about 2,000 ng total HIPVs $\mathrm{g}^{-1}$ leaf tissue (dry wt.) $\mathrm{h}^{-1}$ (Fig. 1a). Defoliation levels were higher in July, averaging 13.1 and $13.4 \%$ on sticky and velvety plants, respectively, but the production of HIPVs dropped to less than $350 \mathrm{ng} \cdot \mathrm{g}^{-1}$
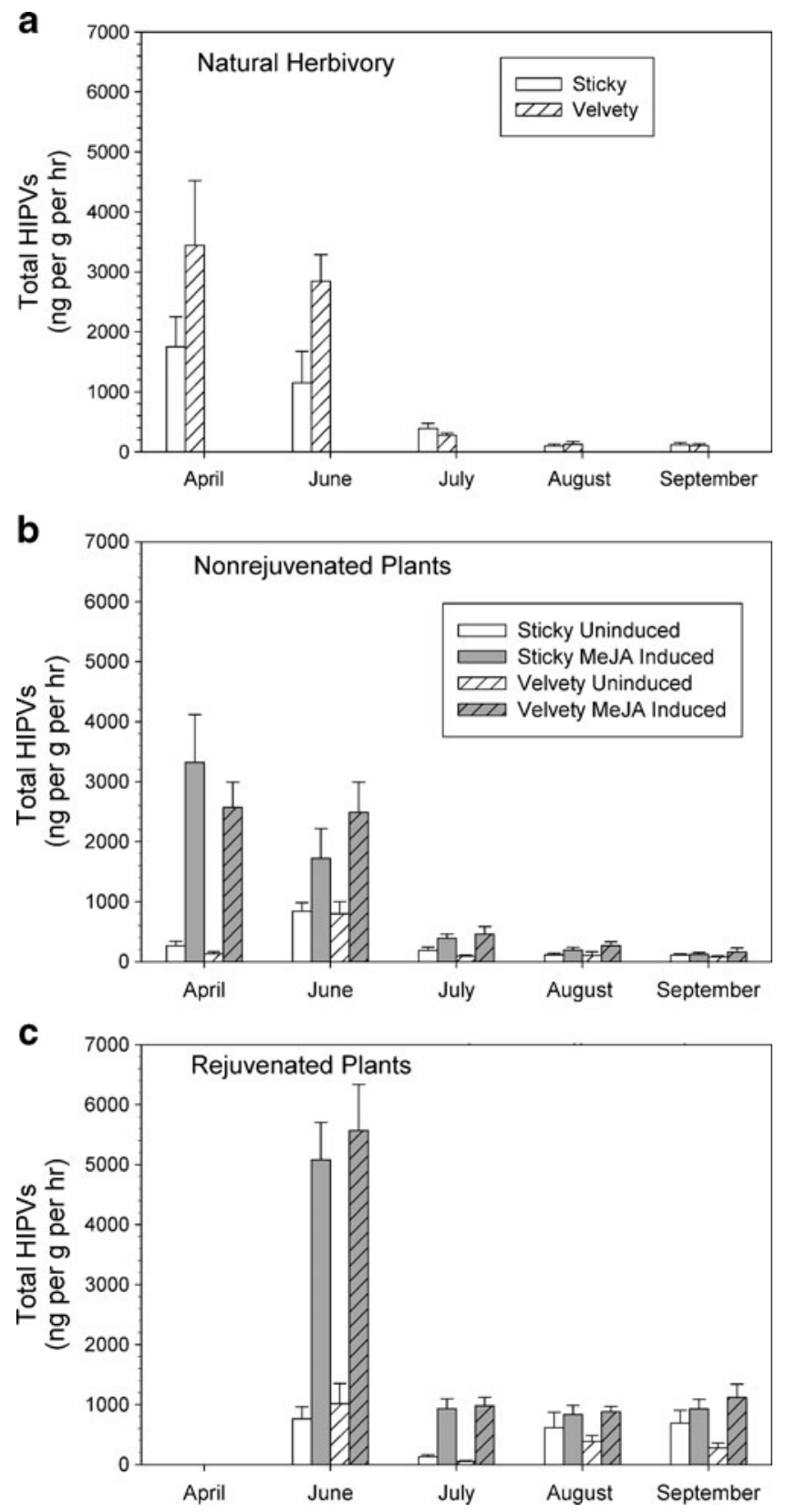

Fig. 1 Total HIPV production in the field for herbivore-damaged Datura wrightii plants (a), and for nonrejuvenated (b) and rejuvenated (c) plants before (Uninduced) and after application of MeJA (MeJA Induced). Mean (+ standard errors) production in $n g \cdot g^{-1}$ (dry wt) leaf $\mathrm{wt} \mathrm{h}^{-1}$ are shown for plants expressing the sticky or velvety trichome phenotype 
leaf tissue (dry wt.) $\mathrm{h}^{-1}$. Plants produced only about $110 \mathrm{ng}$ total HIPVs $\mathrm{g}^{-1}$ leaf tissue (dry wt.) $\mathrm{h}^{-1}$ in August and September in response to herbivory averaging 8.5 and $7.3 \%$ on sticky and velvety plants in August and $8.8 \%$ and $8.4 \%$ in September. There was no linear relationship between percent defoliation and $\log _{10}$ HIPV production overall $(P=0.14$, Fig. 2), nor was there any heterogeneity of slopes between percent defoliation and total HIPV production within sampling dates $(P=0.78)$. Neither did HIPV production differ significantly between trichome types $(P=0.26)$. In summary, herbivory averaging $7-8 \%$ defoliation resulted in the production of nearly 25-fold more HIPVs when inflicted on plants in April than when inflicted in August or September.

MeJA treatment also significantly increased HIPV emission but the amount varied over the season (repeated measures ANOVA, treatment by date interaction $F_{4,149}=$ 22.16, $P<0.001)$. In April, plants emitted nearly 2,700 more ng total HIPVs $\mathrm{g}^{-1}$ leaf tissue (dry wt.) $\mathrm{h}^{-1}$ after MeJA treatment than before treatment, but the difference was cut substantially by June (Fig. 1b). The differences before and after MeJA treatment continued to decline throughout the summer, but were statistically significant from April through August (repeated measures ANOVA, SLICE decomposition of monthly differences, all $F_{1,149} \geq$ 16.32, all $P<0.001)$. The difference in HIPV production before and after MeJA treatment in September was not statistically significant $(P=0.45)$, indicating that MeJA did not induce HIPV production at this time.

All sampled plants successfully resprouted, and the differences in total HIPV production of these rejuvenated plants before and after MeJA treatment always were statistically significant (repeated measures ANOVAs, all $F_{1,120} \geq 19.59$, all $\left.P<0.001\right)$ and ranged from a maximum difference of over 4,000 ng total HIPVs $\mathrm{g}^{-1}$ leaf tissue (dry wt.) $\mathrm{h}^{-1}$ in the June aeration to a low of $365 \mathrm{ng}$ total HIPVs $\mathrm{g}^{-1}$ leaf tissue (dry wt.) $\mathrm{h}^{-1}$ in the August aeration (Fig. 1c). Direct comparison of nonrejuvenated and rejuvenated plants showed that rejuvenated plants produced
Fig. 2 Relationships between total HIPV production $\left(\log _{10} \mathrm{ng} \cdot \mathrm{g}^{-1}\right.$ (dry wt) leaf wt $\mathrm{h}^{-1}$ ) and percent defoliation of Datura wrightii for each monthly aeration for herbivoredamaged plants expressing the sticky (circles) or velvety (triangles) trichome phenotype
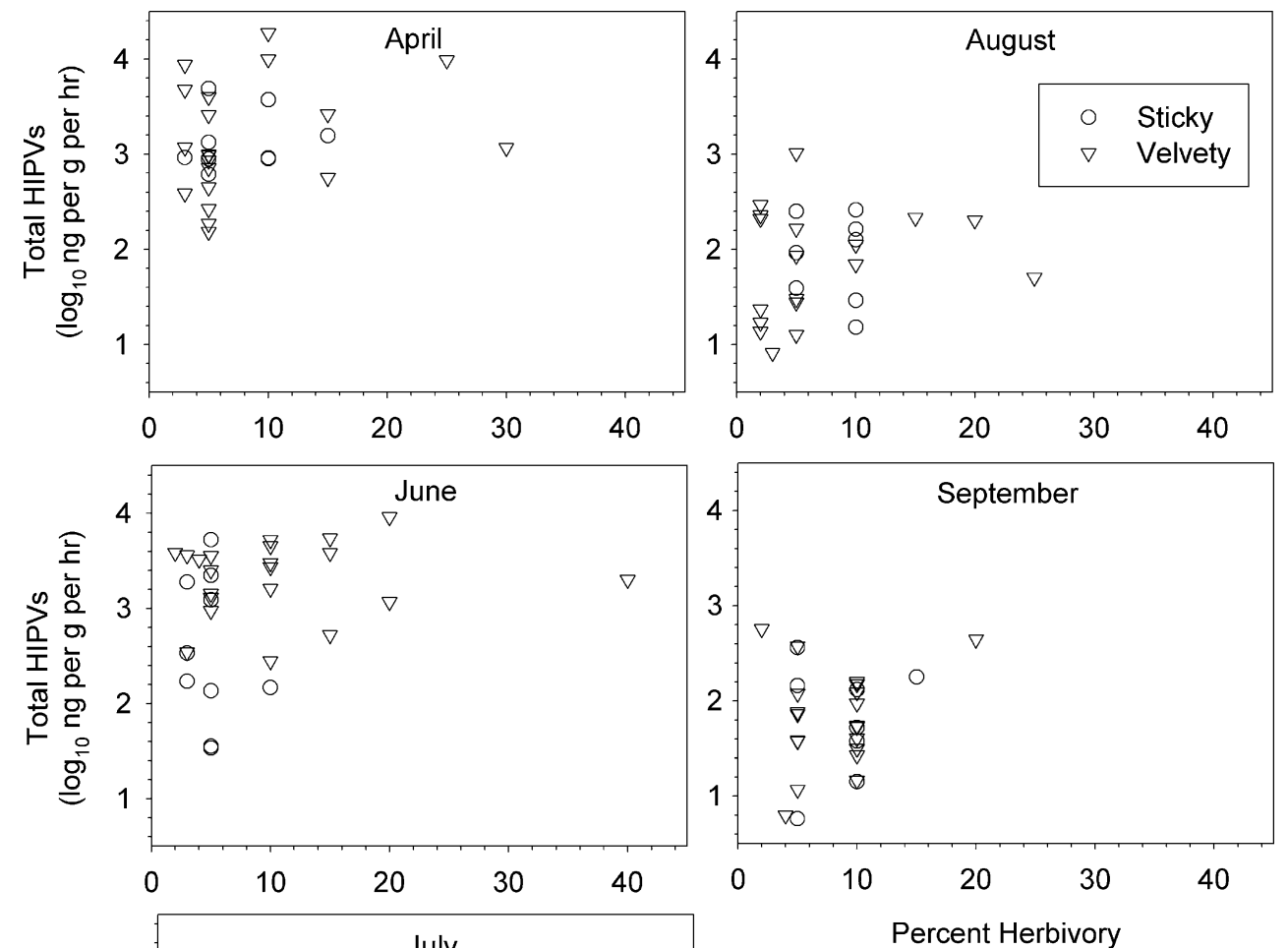

Percent Herbivory

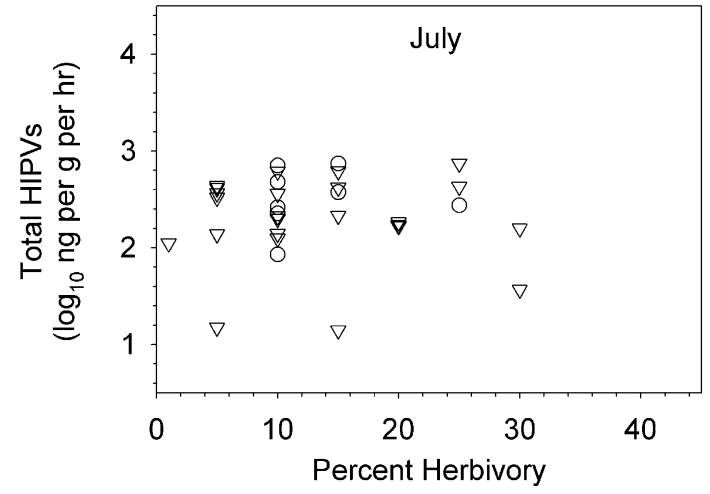


Fig. 3 Plot a: Factor loadings for individual herbivore-induced plant volatiles of Datura wrightii on PC1 and PC 2; Plots b-e: rejuvenated plants; Plots $\mathbf{f}-\mathbf{j}$ : nonrejuvenated and herbivore-damaged plants. Mean ( \pm standard error) factor scores for Principal Components 1 and 2 by trichome type, aeration date, and induction treatment. Triangles: uninduced plants; circles: MeJA-induced plants; squares: herbivoredamaged plants. Open symbols: sticky plants; filled symbols, velvety plants. Chemical abbreviations in Plot a: Cary: $(E)$ - $\beta$-caryophyllene; DMNT: $(E)-4,8$, dimethyl-1,3,7 nonatriene; Far: $(E, E)$ - $\alpha$-farnesene; Hex Ac: $(Z)$-3-hexenyl acetate Hum: $\alpha$-humulene; J: jasmone; Lim: limonene; Lol: linalool; Ner: nerolidol; Oci: $(E)$ - $\beta$-ocimene; T: $(E)-4-$ 8,12 trimethyl-1,3,7,11 tridecatetraene. Overlapping near the origin: $\mathrm{B}$ : $\alpha$-bergamotene; G: geranyl acetone; M: methyl salicylate; $\mathrm{S}$ : $\beta$-selinene

significantly greater quantities of HIPVs after treatment with MeJA, (repeated measures ANOVA rejuvenation effect $\left.F_{1,269}=61.55, P<0.001\right)$, but the differences declined over the season (rejuvenation by date interaction $F_{3,269}=$ $9.85, P<0.001$, Fig. 1b, c). For neither non-rejuvenated nor rejuvenated plants did total HIPV production vary with trichome phenotype (all $P \geq 0.09$ ).

PCA analysis yielded seven components whose eigenvalues were greater than 1.0 , and the first component (PC 1) accounted for $50.3 \%$ of the total variance in the data. Principal Components \# 2 through 7 accounted for 8.0, 7.1, $6.4,5.7,4.8$, and $4.2 \%$ of the total variance, respectively, for a total of $86.5 \%$. All original variables except nerolidol and TMTT had positive loadings on PC 1 , indicating that this component can be interpreted largely as a "general production" factor much like a "general size" factor in morphological studies. The highest factor loadings were for $(E)-\beta$ ocimene and (E)- $\beta$-caryophyllene (Fig. 3a), and plants that emitted relatively greater quantities of $(E)-\beta$-ocimene and (E)- $\beta$-caryophyllene had relatively higher scores on PC 1 .

The original variables loaded positively or negatively on PC 2, indicating differences in the composition of the HIPV blends. PC 2 contrasts plants that, among other differences, had higher concentrations of (Z)-3-hexenyl acetate and DMNT with plants that produced higher concentration of the sesquiterpenes, $\alpha$-humulene, or $(E)$ - $\beta$-caryophyllene (Fig. 3a). The remaining principal components generally contrasted particular compounds of limited occurrence that were not easily interpreted, so detailed analyses were carried out only for PC 1 and PC 2.

Factor scores for PC 1 were greater for MeJA-treated plants or herbivore-damaged plants than uninduced plants to varying amounts, depending upon aeration date, induction method, and rejuvenation treatment (Fig. 3b-e for rejuvenated plants and Fig. $3 \mathrm{f}-\mathrm{j}$ for nonrejuvenated and herbivore-damaged plants); scores for PC 1 reflected patterns similar to those for total HIPVs (Fig. 1). The changes in factor scores for PC 2 were more variable among aeration dates and treatments. There was relatively little change factor scores for PC 2 before and after MeJA treatment for nonrejuvenated plants in April and rejuvenated plants in June (Fig. 3f, b), indicating
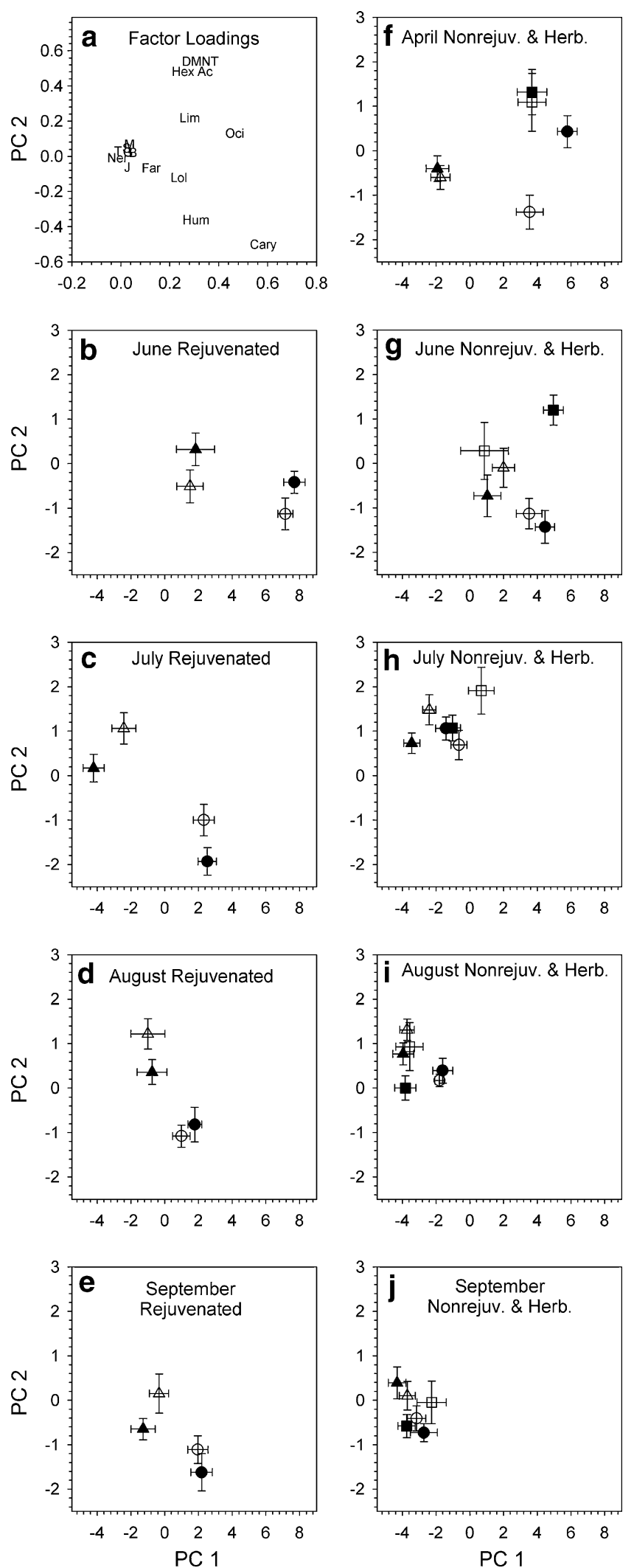
that the blends were greater in concentration but similar in composition after induction. Substantial changes in scores for PC 2 were observed in the post-treatment aerations for rejuvenated plants in July, August, and September (Fig. 3c-e) and for herbivore-damaged plants in April (Fig. 3f). The relatively greater negatives scores for PC 2 post-induction in the rejuvenated plants reflect relatively higher production of (E)- $\beta$-caryophyllene and other compounds with high negative loadings for PC 2 in rejuvenated plants. The differences in composition of HIPV blends from nonrejuvenated plants before and after induction declined in the later aerations, however, as shown by similar scores for PC2 in July through September (Fig. 3h-j).

The high factor loadings for (Z)-3-hexenyl acetate, $(E)$ $\beta$-ocimene, DMNT, and $(E)-\beta$-caryophyllene (Fig. 3a) on PC1 and/or PC 2 justified more detailed analyses of these particular compounds. For herbivore-damaged plants, all of these major compounds were produced in significantly higher concentrations in April and June than in July through September (ANOVA; all date effects $P<0.001$, Fig. 4a, d, g, j). For MeJA-treated plants, (Z)-3-hexenyl acetate was generally the most abundant HIPV prior to MeJA treatment, but the ability of MeJA to induce higher levels of this compound was inconsistent in both nonrejuvenated and rejuvenated plants over time (repeated measures ANOVA, treatment by date interaction $F_{4,149}=$ 5.32, $P<0.001$ for non-rejuvenated plants and $F_{3,120}=7.23$, $P<0.001$, for rejuvenated plants, Fig. $4 \mathrm{~b}, \mathrm{c}) .(E)-\beta-$ Ocimene and $(E)$ - $\beta$-caryophyllene were induced consistently by MeJA in rejuvenated plants and relatively young nonrejuvenated plants, but less so in older nonrejuvenated plants $[(E)-\beta$-ocimene: MeJA treatment by date interaction $F_{4,149}=21.55, P<0.001$ for nonrejuvenated plants and $F_{3}$, ${ }_{120}=8.41, P<0.001$ for rejuvenated plants; $(E)$ - $\beta$-caryophyllene: MeJA treatment by date interaction $F_{4}, 149=9.34$, $P<0.001$ for nonrejuvenated plants and $F_{3}, 120=13.90$, $P<0.001$ for rejuvenated plants, Fig. 4h, i, k, 1]. More variable results were obtained for DMNT (MeJA treatment by date interaction $F_{4,149}=28.09, P<0.001$ for nonrejuvenated plants and $F_{3,120}=7.58$ for rejuvenated plants, Fig. 4e, f). Rejuvenated plants produced significantly more quantities of $(E)$ - $\beta$-ocimene and $(E)$ - $\beta$-caryophyllene than non-rejuvenated plants (all rejuvenation treatment effects $P>0.003$ ) although the magnitude of the differences varied over the season (all rejuvenation treatment by date interactions $P<0.004$ ).

In summary, the composition of the HIPV blends varied over the season as a result of quantitative differences in the induction of different HIPVs at different times. The induced blend of herbivore-damaged and nonrejuvenated plants was dominated by $(E)-\beta$-caryophyllene in April and June and comprised ca. $44-49 \%$ of all HIPVs, depending upon trichome phenotype and sampling date in plants subjected to natural herbivory, and $60-75 \%$ in MeJA-treated plants. (Z)-3-hexenyl acetate predominated in non-rejuvenated and herbivore-damaged plants later in the season. The blend of rejuvenated plants, however, was always dominated by $(E)$ $\beta$-caryophyllene although the relative proportions varied among aeration dates.

Insect Abundances All sampled plants were infested with L. daturaphila, and all sampled sticky plants were infested with $T$. notatus in the first census, and the infestation rate of L. daturaphila never dropped below $85 \%$. Similarly, the infestation rate of $T$. notatus never dropped below $67 \%$. The infestation rate of $G$. pallens was more variable, ranging from 0 and $26 \%$ of sticky and velvety plants in the first census to between $57-100 \%$ of all plants irrespective of trichome phenotype through mid-September. After an initial peak following colonization of plants in the spring, densities of larvae of $L$. daturaphila declined to a range of from 3-35 per plant throughout the remainder of the season (ANOVA, census date effect $F_{10},{ }_{153}=6.25, P<0.001$, Fig. 5a). Abundances did not differ significantly between sticky and velvety phenotypes $(P=0.92)$ nor did the census date by time interaction $(P=0.27)$. Densities of $T$. notatus increased from ca. 28 per plant at the beginning of the season to over 200 per plant in mid-August, but because of the large variation within censuses, the differences in densities did not differ significantly among censuses $(P=$ 0.21 , Fig. 5b). Densities of $G$. pallens also showed a seasonal peak in the spring but then declined to a range of from 1-5 per plant for the remainder of the season (census date effect $F_{10,153}=7.91, P<0.001$, Fig. 5c). Surprisingly, abundances of $G$. pallens were significantly greater on sticky than velvety plants throughout the season (phenotype effect $F_{1,153}=7.97, P=0.005$ ). Observations of egg masses of $L$. daturaphila showed evidence of predation by $G$. pallens, throughout the season, but predation was not quantified.

\section{Discussion}

The ability of $D$. wrightii to increase HIPV production in response to natural herbivory and treatment with MeJA is constrained seasonally and by ontogenetic stage. Greater quantities of induced HIPVs were produced by induced plants during the two aerations in the spring, when plants were growing vegetatively and had not yet begun to flower, than in the summer when plants continued to grow vegetatively but also began flowering and fruiting. The ability of plants to emit HIPVs in response to MeJA treatment during the three summer aerations was restored partially by cutting the plants back to ground level and allowing them to produce new foliage from the root crown. 


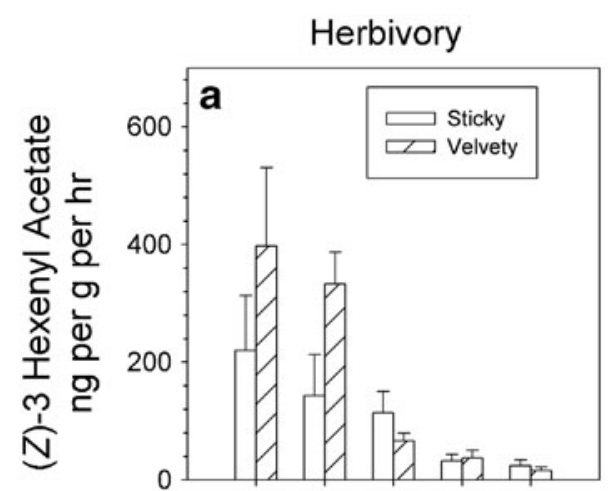

Nonrejuvenated
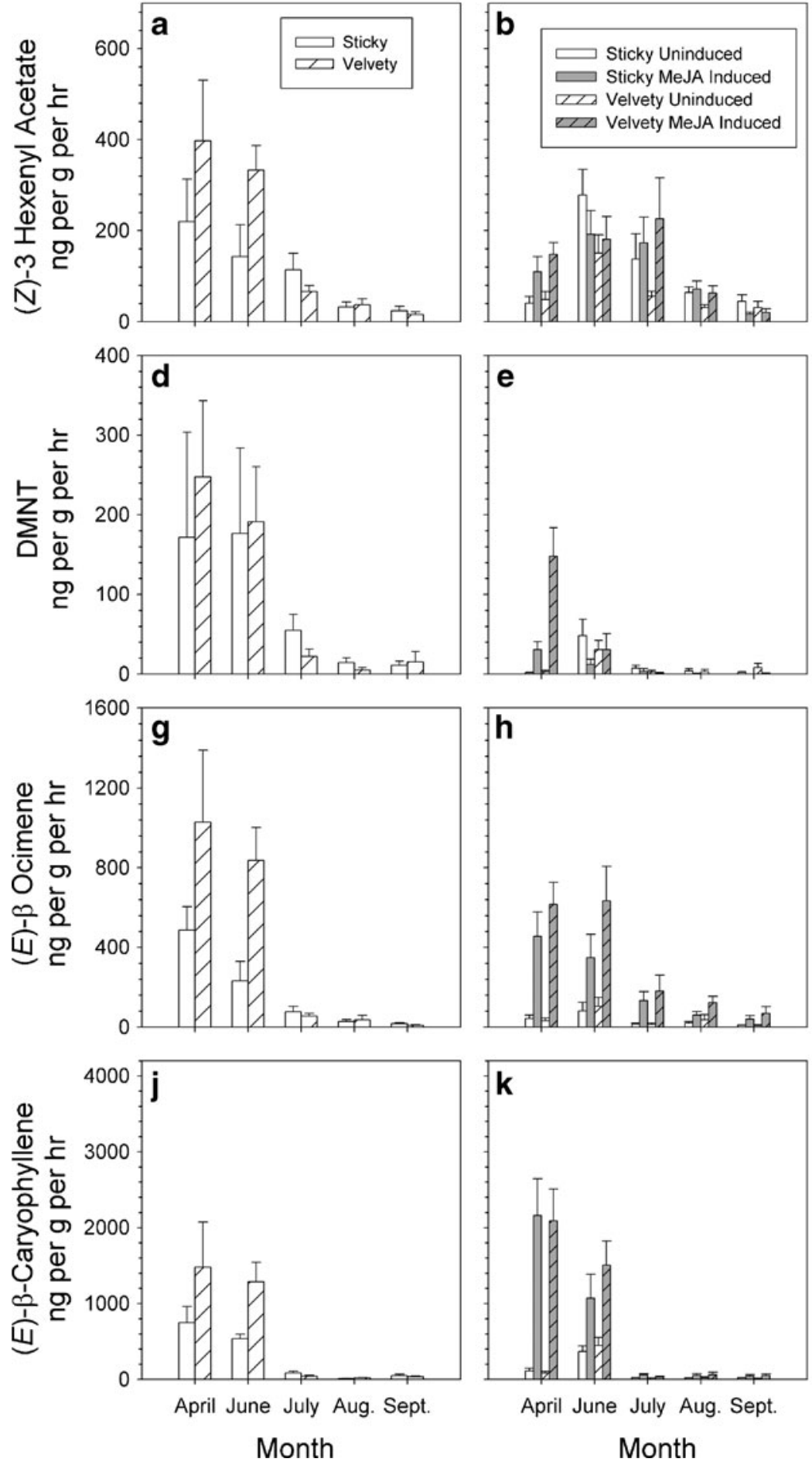

Fig. 4 Production of (Z)-3-hexenyl acetate, DMNT, $(E)$ - $\beta$-ocimene, and $(E)-\beta$ caryophyllene in the field for herbivore-damaged Datura wrightii plants, and nonrejuvenated and rejuvenated plants before

Although the HIPV production of rejuvenated plants was significantly greater than nonrejuvenated plants during each of the three summer aerations, it always was lower than nonrejuvenated plants in the spring.
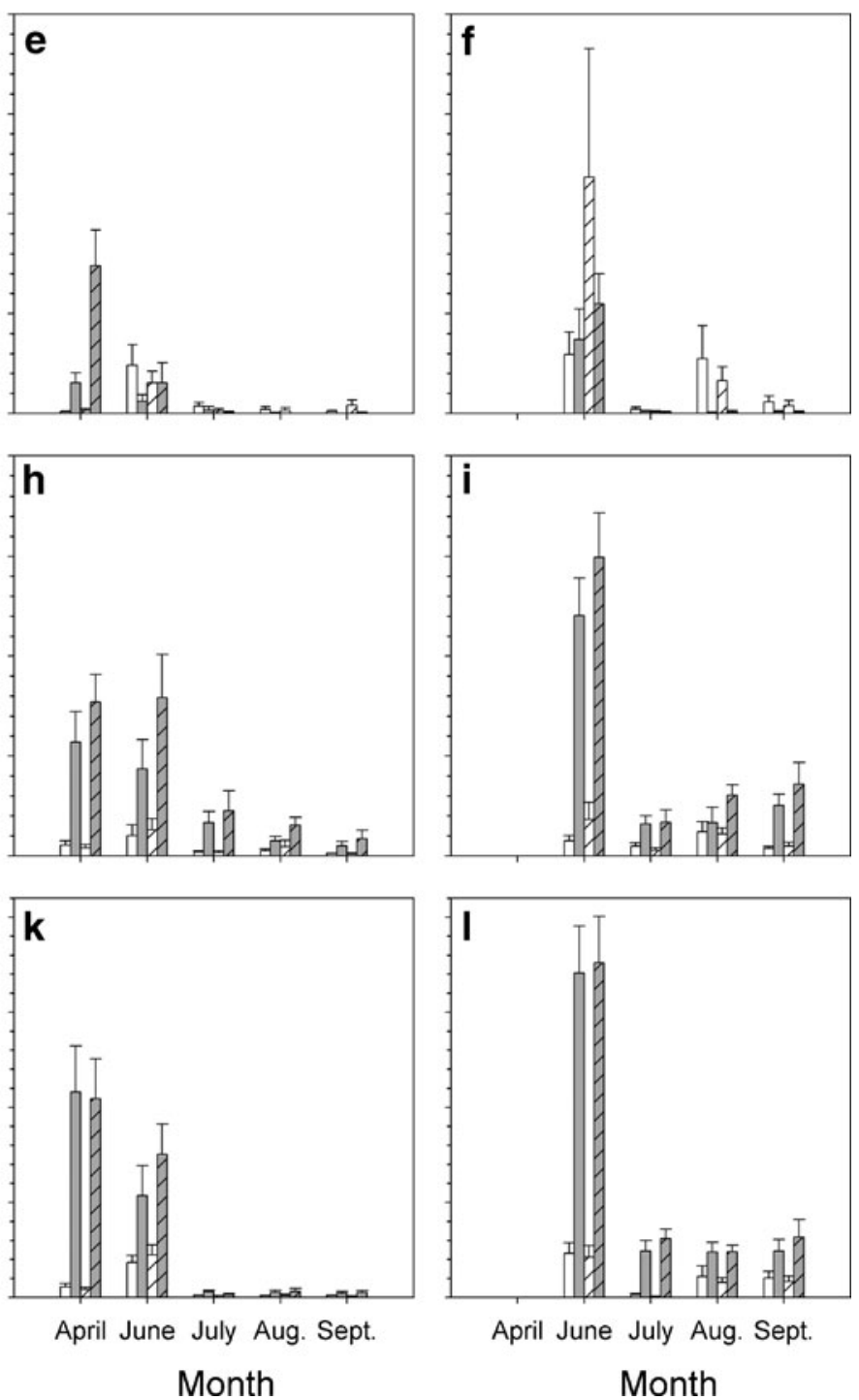

(Uninduced) and after application of MeJA (MeJA Induced). Mean (+ standard errors) in $\mathrm{ng} \cdot \mathrm{g}^{-1}$ (dry wt.) leaf $\mathrm{hr}^{-1}$ are shown for plants expressing the sticky or velvety trichome phenotype

The relatively high proportion of $(E)-\beta$-caryophyllene in young plants is consistent with previous laboratory work with this system (Hare, 2007), and it suggests that this may be one compound that is differentially induced during the 

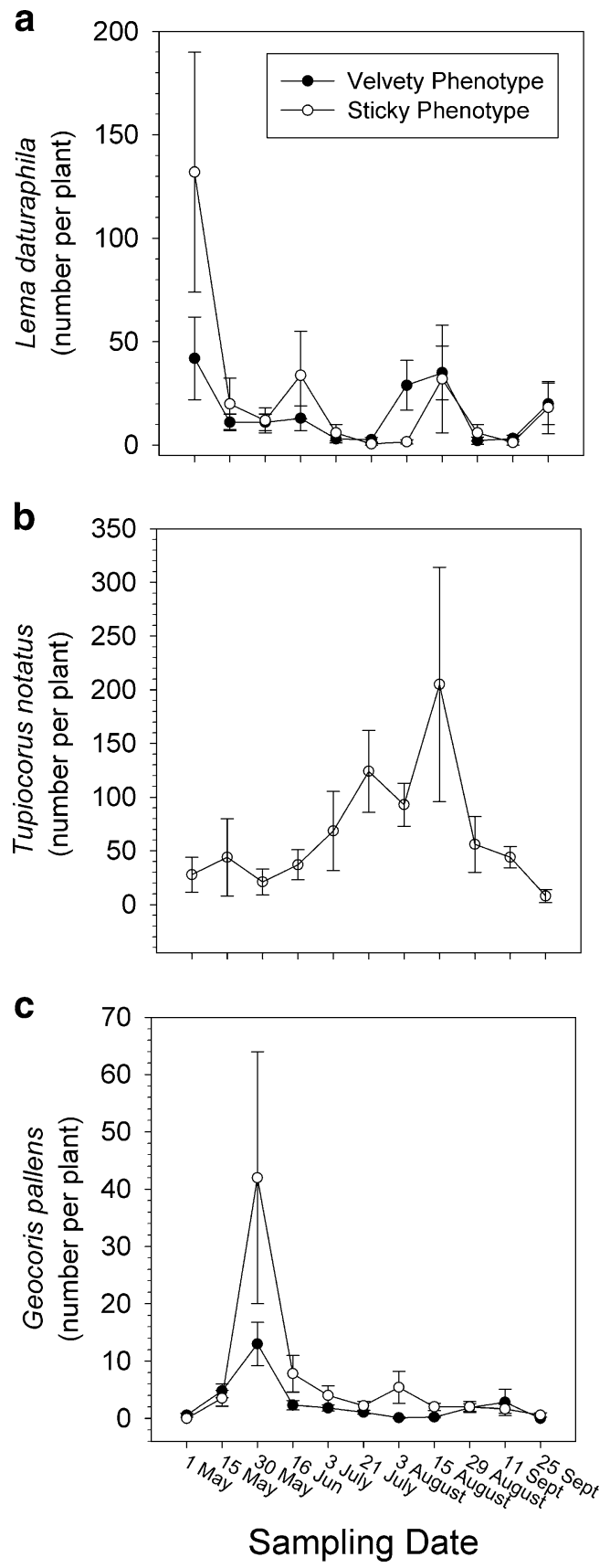

Fig. 5 Densities per plant of motile stages of the herbivores Lema daturaphila (a), Tupiocoris notatus (b), and the predator Geocoris pallens (c) sampled from Datura wrightii every 2 weeks. Means ( \pm standard errors) are shown

earlier stages of plant ontogenetic development. Over time, however, the production of $(E)$ - $\beta$-caryophyllene in older plants declined, leaving the blend of induced HIPVs relatively richer in (Z)-3-hexenyl acetate later in the summer.

Because of the potential for seasonal variation in the inducibility of HIPV production in response to natural herbivory, it was important to attempt to separate the effect of seasonally varying factors, such as temperature and humidity, from endogenous aspects of plant development that might have caused induced HIPV production to vary. One approach to separate seasonality from ontogeny might have been to transplant fresh seedlings to the field at different times during the summer (Thaler et al., 1996), but this would have been ecologically unrealistic with regard to natural germination of $D$. wrightii, as well as logistically difficult to establish transplants in the field during the heat of the summer. The observation that plants completely defoliated by herbivores resprout with juvenile foliage and then redifferentiate (Elle et al., 1999) suggested a different, more ecologically relevant approach toward separating seasonal from ontogenetic variation in HIPV production. This approach simply required that mature plants be cut back and allowed to resprout. This manipulation restored HIPV production, but to varying extents depending upon when during the season the plants were cut back. Thus, both seasonal and ontogenetic factors may constrain inducible HIPV responses in $D$. wrightii. The rejuvenated plants also served as a positive control and showed that the lower levels of HIPVs from unrejuvenated plants in the three summer aerations compared to the two spring aeration were not simply the result of any environmental factor that might preclude HIPV collection during the summer.

It is well-established that induced direct defenses are more pronounced in younger plant tissues (Thaler et al., 1996; Karban and Baldwin, 1997; van Dam et al., 2001), but relatively little is known as to the potential age-related variation in inducible HIPV production. In maize, HIPV production of leaves could be induced in 14-d-old seedlings but not in mature leaves (Köllner et al., 2004). HIPV production was an order of magnitude higher in vegetative stages of soybean than in flowering plants (Rostas and Eggert, 2008). This limited evidence, along with the present study, suggests that, as with inducible direct defenses, induced HIPV production may also be maximized in relatively young tissues.

Under natural conditions, $D$. wrightii is embedded in a community of plants, each with their own communities of herbivores and natural enemies. Plants occur in patches that persist for several years (Hare and Elle, 2004). Individual plants within patches quickly become colonized by overwintering adults of $L$. daturaphila, $T$. notatus, and other herbivores in the early spring, then suffer chronic herbivory throughout the growing season. Plants also are colonized by G. pallens and other generalist natural enemies at about the same time (Gassmann and Hare, 2005). Only two species of parasitoid have been recovered from southern California L. daturaphila populations, and these are the tachinid fly, Myiopharus infernalis, and the chalcid wasp, Conura delumbis. The host range of both are poorly known but include, at least, other species of beetles from nonsolanaceous plant species (Arnaud, 1978; Burks, 1979). 
Both parasitoids also are most abundant in late summer (J. D. Hare, pers. obs., see also Puttler (1966)).

The original goal of this study was to understand the potential for $D$. wrightii to release HIPVs that may attract natural enemies of its herbivores. The temporal pattern of abundance of insects and HIPV production suggests several possibilities. In view of the rapid colonization of plants by both herbivores and natural enemies, it may not be beneficial for $D$. wrightii to produce any "long-range" cues except perhaps in the early spring, when some plants are colonized by herbivores but most are not. Using a modeling approach, Puente et al. (2008a) concluded similarly that "the utility of the volatile cues is consistently greater when a smaller proportion of plants is occupied by herbivores, indicating that their usefulness may be reduced to zero in fields saturated with volatiles," presumably when all plants are finally discovered and damaged by herbivores. On the other hand, if natural enemies can respond quantitatively as well as qualitatively to HIPVs, then plants producing stronger or more desirable cues may benefit over plants that produce weaker cues even when all plants are infested.

A possible explanation that would be consistent with the greater HIPV production by young $D$. wrightii plants is based upon the "optimal defense" theory of defense against herbivores. Optimal defense theory is based upon the premise that the allocation of resources is determined by the net result of the costs of that defense balanced against its benefit in terms of plant fitness (McKey, 1974). One consequence of this is the prediction that defensive traits should be maximally deployed during stages of high risk and/or low tolerance (Boege and Marquis, 2005). Although L. daturaphila densities were highest in the spring, those of $T$. notatus were not, and these species have shown different seasonal patterns of abundance in southern California; particularly a secondary peak usually occurred in late September and October in other years (Elle and Hare, 2000; Hare and Elle, 2002). It may be difficult to identify periods of differential risk of herbivory based upon the persistent abundance of these two herbivore species. A more likely application of the optimal defense theory in this system would be based upon ontogenetic variation in tolerance to herbivory. As $D$. wrightii grows, the plants produce a large, fleshy tap root that stores carbohydrate. Possibly, the ability of $D$. wrightii to tolerate herbivory increases with age such that continued allocation to defense, including HIPV production, becomes progressively less beneficial, possibly accounting for the seasonal decline in HIPV production.

Additionally, induced volatiles may be adaptive to $D$. wrightii for reasons other than, or in addition to, mediating herbivore-natural enemy interactions. In other systems, for example, some HIPVs confer resistance against herbivores or pathogens, and others mitigate abiotic stresses (Holopainen, 2004; Penuelas and Llusia, 2004; Dudareva et al., 2006;
Gershenzon and Dudareva, 2007). Although no such studies have yet been undertaken in $D$. wrightii to evaluate these possibilities, they cannot be ignored. Such additional roles, of course, would introduce substantial complications into the study of the production of HIPVs by $D$. wrightii and in assessing how and when HIPVs might benefit plant fitness (Dicke and Baldwin, 2010). Finally, it also is possible that HIPV production is merely a genetically correlated consequence of other induced plant responses to herbivore damage and incidental to the interactions between $D$. wrightii's herbivores and their natural enemies. Nevertheless, current results suggest the testable hypothesis that, by whatever combination of mechanisms, any benefits of HIPV production by $D$. wrightii, as well as any natural selection on $D$. wrightii genotypes that favors different quantities or blends of HIPVs (Hare, 2007), may be confined largely to the early periods of vegetative growth when HIPV production is greatest.

Most research on HIPVs has been performed in the laboratory and on cultivars of domesticated plant species (Dicke and Baldwin, 2010), and this is one of a few studies to investigate the seasonal variation in the production of induced HIPVs of an undomesticated plant species under field conditions. Results generally support previous laboratory studies on $D$. wrightii showing that young, vegetative plants can be induced to produce HIPVs. The laboratory studies, however, were performed only on young plants and were insufficient to capture both the dynamic change in the ability of plants to produce HIPVs over the course of the natural growing season and the changes in the composition of those HIPV blends. That the induced HIPV response of $D$. wrightii is largely confined to ontogenetically young tissues is consistent with studies in other systems showing that other induced plant responses are largely confined to young plants (Karban and Baldwin, 1997; Boege and Marquis, 2005). It is perhaps less obvious that HIPV production in $D$. wrightii is well-matched to the patterns of seasonal abundance of $D$. wrightii's herbivores and their natural enemies.

Acknowledgments I thank A. Phan, T. J. Burhans, A. Cossette, and T. Spencer for field and laboratory assistance and M. Turcotte, J. Sun, N. M. van Dam, and J. G. Millar for comments on previous drafts of this manuscript. This research was supported by the National Science Foundation under Grant No. NSF DEB 0414181.

Open Access This article is distributed under the terms of the Creative Commons Attribution Noncommercial License which permits any noncommercial use, distribution, and reproduction in any medium, provided the original author(s) and source are credited.

\section{References}

Allison, J. D. and HARE, J. D. 2009. Learned and naïve natural enemy responses and the interpretation of volatile organic compounds as cues or signals. New Phytol. 184:768-782. 
ARNAUD, P. H. 1978. A host-Parasite Catalog of North American Tachinidae (Diptera). USDA Miscellaneous Publication \# 1319. Washington, D. C. U. S. Dept. of Agriculture, Science and Education Administration, $860 \mathrm{p}$.

BoEge, K. and MARQUiS, R. J. 2005. Facing herbivory as you grow up: The ontogeny of resistance in plants. Trends Ecol. Evol. 20:441-448.

Bruinsma, M., Posthumus, M. A., Mumm, R., Mueller, M. J., VAN LOON, J. J. A., and DiCKE, M. 2009. Jasmonic acid-induced volatiles of Brassica oleracea attract parasitoids: Effects of time and dose, and comparison with induction by herbivores. J. Exp. Bot. 60:2575-2587.

Burks, B. D. 1979. Chalcididae, pp. 860-873, in K. V. Krombein, P. D. HuRd, O. R. SMith and B. D. Burks, (eds.). Catalog of Hymenoptera in America North of Mexico. Smithsonian Institution Press, Washington, D. C.

Dicke, M. and BALDWIN, I. T. 2010. The evolutionary context for herbivore-induced plant volatiles: Beyond the 'cry for help'. Trends Plant Sci. 15:167-175.

Dicke, M., Gols, R., Ludeking, D., and Posthumus, M. A. 1999. Jasmonic acid and herbivory differentially induce carnivoreattracting plant volatiles in lima bean plants. J. Chem. Ecol. 25:1907-1922.

Dudareva, N., Negre, F., Nagegowda, D. A., and Orlova, I. 2006. Plant volatiles: Recent advances and future perspectives. Crit. Rev. Plant Sci. 25:417-440.

Elle, E. and Hare, J. D. 2000. No benefit of glandular trichome production in natural populations of Datura wrightii? Oecologia 123:57-65

Elle, E., VAn Dam, N. M., and Hare, J. D. 1999. Cost of glandular trichomes, a "resistance" character in Datura wrightii Regel (Solanaceae). Evolution 53:22-35.

GASSMANN, A. J. and HARE, J. D. 2005. Indirect cost of a defensive trait: Variation in trichome type affects the natural enemies of herbivorous insects on Datura wrightii. Oecologia 144:62-71.

GERShENZON, J. and DUdAREVA, N. 2007. The function of terpene natural products in the natural world. Nat. Chem. Biol. 3:408-414.

Gouinguene, S. P. and TuRLINGS, T. C. J. 2002. The effects of abiotic factors on induced volatile emissions in corn plants. Plant Physiol. 129:1296-1307.

Halitschke, R., Stenberg, J. A., Kessler, D., Kessler, A., and BALDWIN, I. T. 2008. Shared signals-'alarm calls' from plants increase apparency to herbivores and their enemies in nature. Ecol. Lett. 11:24-34.

HARE, J. D. 2007. Variation in herbivore and methyl jasmonateinduced volatiles among genetic lines of Datura wrightii. J. Chem. Ecol. 33:2028-2043.

HARE, J. D. and ElLE, E. 2002. Variable impact of diverse insect herbivores on dimorphic Datura wrightii. Ecology 83:2711-2720.

HARE, J. D. and ElLE, E. 2004. Survival and seed production of sticky and velvety Datura wrightii in the field: A five-year study. Ecology 85:615-622.

HaRe, J. D., Elle, E., and VAN DAm, N. M. 2003. Costs of glandular trichomes in Datura wrightii: A three-year study. Evolution 57:793-805.

Holopainen, J. K. 2004. Multiple functions of inducible plant volatiles. Trends Plant Sci. 9:529-533.

Hopke, J., Donath, J., Blechert, S., and Boland, W. 1994. Herbivore-induced volatiles - the emission of acyclic homo- terpenes from leaves of Phaseolus lunatus and Zea mays can be triggered by a beta-glucosidase and jasmonic acid. FEBS Lett. 352:146-150.

Karban, R. and Myers, J. H. 1989. Induced plant responses to herbivory. Annu. Rev. Ecol. Syst. 20:331-348.

KARBAN, R. and BALDWIN, I. T. 1997. Induced responses to herbivory. Pp. 319. University of Chicago Press, Chicago.

KESSLER, A. and BALDWIN, I. T. 2001. Defensive function of herbivore-induced plant volatile emissions in nature. Science 291:2141-2144.

Köllner, T. G., Schnee, C., Gershenzon, J., and Degenhardt, J. 2004. The sesquiterpene hydrocarbons of maize (Zea mays) form five groups with distinct developmental and organ-specific distribution. Phytochemistry 65:1895-1902.

MCKEY, D. 1974. Adaptive patterns in alkaloid physiology. Am. Nat. 108:305-320.

Penuelas, J. and Llusia, J. 2004. Plant VOC emissions: Making use of the unavoidable. Trends Ecol. Evol. 19:402-404.

Puente, M. E., Kennedy, G. G., and Gould, F. 2008a. The impact of herbivore-induced plant volatiles on parasitoid foraging success: A general deterministic model. J. Chem. Ecol. 34:945-958.

Puente, M. E., Magori, K., Kennedy, G. G., and Gould, F. 2008b. Impact of herbivore-induced plant volatiles on parasitoid foraging success: A spatial simulation of the Cotesia rubecula, Pieris rapae, and Brassica oleracea system. J. Chem. Ecol. 34:959970.

PutTleR, B. 1966. Notes on two parasites attacking a Lema species (Coleoptera : Chrysomelidae). J. Econ. Entomol. 59:475-476.

Rostas, M. and EGGERT, K. 2008. Ontogenetic and spatio-temporal patterns of induced volatiles in Glycine $\max$ in the light of the optimal defence hypothesis. Chemoecology 18:29-38.

SAS INSTITUTE. 2008. SAS for windows version 9.2. SAS Institute. Cary, N. C.

Stout, M. J., Workman, K. V., Workman, J. S., and Duffey, S. S. 1996. Temporal and ontogenetic aspects of protein induction in foliage of the tomato, Lycopersicon esculentum. Biochem. Syst. Ecol. 24:611-625.

Thaler, J. S., Stout, M. J., Karban, R., and Duffey, S. S. 1996. Exogenous jasmonates simulate insect wounding in tomato plants (Lycopersicon esculentum) in the laboratory and field. J. Chem. Ecol. 22:1767-1781.

TURLINGS, T. C. J. and WÄCKERS, F. 2004. Recruitment of predators and parasitoids by herbivore-injured plants. pp. 21-75, in R. T. Cardé and J. G. Millar, (eds.). Advances in Insect Chemical Ecology. Cambridge University Press, Cambridge.

VAN DAM, N. M. and HARE, J. D. 1998. Differences in distribution and performance of two sap-sucking herbivores on glandular and non-glandular Datura wrightii. Ecol. Entomol. 23:22-32.

VAN DAM, N. M., HARE, J. D., and Elle, E. 1999. Inheritance and distribution of trichome phenotypes in Datura wrightii. J. Hered. 90:220-227.

VAn DaM, N. M., Horn, M., Mares, M., and Baldwin, I. T. 2001. Ontogeny constrains systemic protease inhibitor response in Nicotiana attenuata. J. Chem. Ecol. 27:547-568.

VAN DAM, N. M. and POPPY, G. M. 2008. Why plant volatile analysis needs bioinformatics - detecting signal from noise in increasingly complex profiles. Plant Biol. 10:29-37.

VInSON, S. B. 1976. Host selection by insect parasitoids. Annu. Rev. Entomol. 21:109-133. 